\title{
Reflexiones en torno a la Conservación-Restauración de los muebles del pasado
}

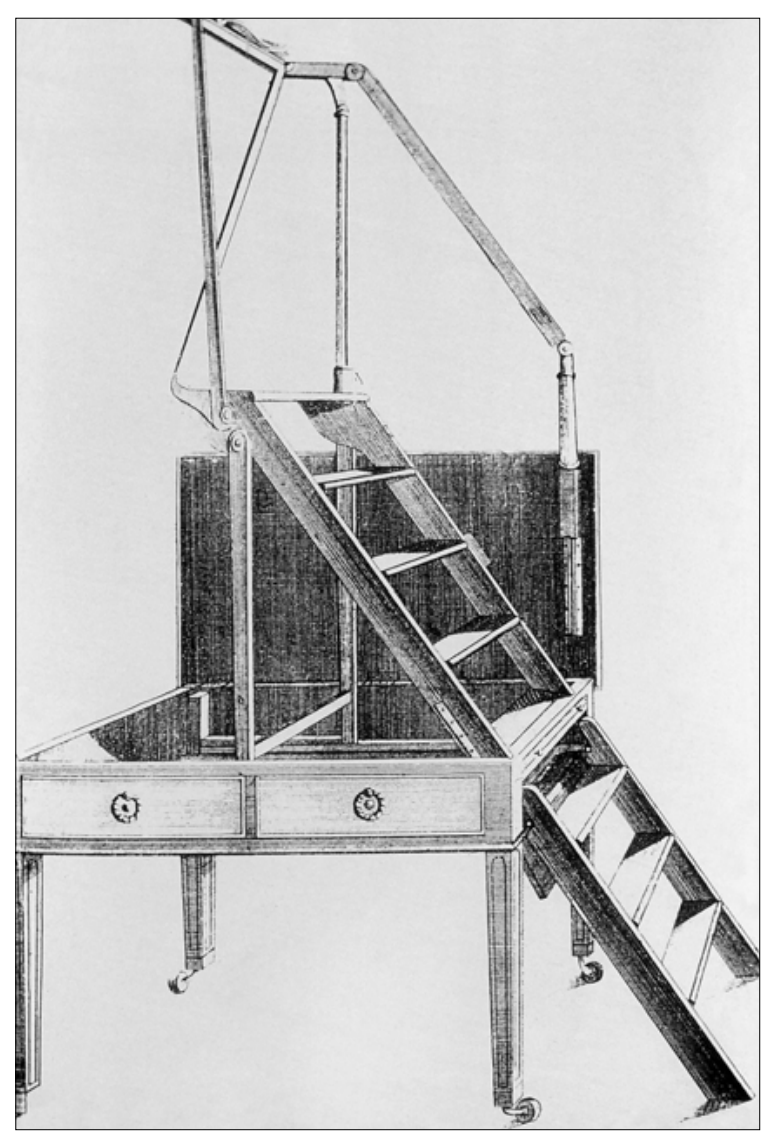

Cristina y Leticia Ordóñez

Equipo Arcaz

\section{Resumen}

Tras exponer una serie de consideraciones en torno a la valoración cultural del mobiliario del pasado, se hace referencia a una de las fases metodológicas de la restauración de este tipo de objetos: la reparación estructural. Una fase de la intervención, en muchos casos polémica, que se ilustra mediante ejemplos concretos.

\section{Palabras clave}

Mobiliario / Memoria histórica / Valor artístico / Valor simbólico / Reparación estructural.

\section{Preámbulo}

Resulta verdaderamente sorprendente, además de decepcionante, el hecho de que en un mundo cultural que parecía haber roto ya con una concepción jerarquizada del arte, aún siga siendo necesario salir en defensa de los muebles del pasado para reivindicar sus valores culturales. Para rebatir la consideración que, en la mente de muchas personas, se tiene de ellos como simples objetos "de adorno". O también como fríos artefactos utilitarios marcados por una aséptica funcionalidad que les priva de cualquier otro significado.

Estos gratuitos planteamientos, que denotan un profundo desconocimiento del mobiliario del pasado, podrían derivar de la vieja división de las artes en mayores y menores, de la separación entre arte puro y arte útil. Una ruptura que hoy en día carece de fundamento ya que, a lo largo de la historia, el 
don creativo y la maestría artesanal se han manifestado sin jerarquías en cualquier tipo de producción artística.

Los muebles nacieron para responder a ciertas necesidades del ser humano, tanto práticas o materiales como espirituales o estéticas. Es cierto que muchos de ellos fueron construidos con el fin de que desempeñaran unas funciones concretas; debían de ser utiles. Pero dicha utilidad, cuidadosamente prevista y diseñada, lejos de restar valor a estos objetos, les atribuía unas cualidades que nos permiten ahora profundizar en torno al significado humano de la necesidad Sobre el mérito de conseguir que éstos fueran además bellos!.

No obstante, en numerosas ocasiones, la intencionalidad estética de ciertos muebles relegó su función de uso a un segundo plano o incluso la anuló por completo.

En este sentido cabe mencinar a Alvar Gonzalez Palacios cuando afirma que desde siempre se han creado muebles inútiles.Y para ilustrar esta afirmación, se refiere a unas pequeñas mesas para escribir ejecutadas por Martin Carlin en el siglo XVIII. Unas mesitas cuyas superficies recubiertas de bronces "afilados como dagas" y de placas de porcelana "frágiles como cristales", impedían realizar dicha tarea. Y por ende, estaban destinadas a mujeres analfabetas que nunca escribían ${ }^{2}$. Como vemos, en estas obras existe una intencionada e irónica falta de coherencia entre forma y función.

Pero los muebles son muchas más cosas que útiles o inutiles. Sin entrar en cuestiones de estética, nos limitaremos a constatar que son Bienes culturales que hay que respetar y preservar. Y para ello será necesario empezar por superar la mencionada dicotomía entre artes mayores y menores. De esta manera se pondrá punto final a la situación de inferioridad y de desamparo en la que todavía se encuentra este rico sector de nuestro Patrimonio. Por eso para aportar, con ocasión de este articulo, nuestro granito de arena de cara a la revalorización del mobiliario del pasado, nos referiremos a continuación al significado cultural del mismo.

\section{Valores culturales de mobiliario}

Los muebles del pasado poseen unos atributos culturales cuyo conocimiento es imprescindible para poder realizar una lectura adecuada y completa de ellos. Esto nos permitirá situarlos en el lugar que, por meritos propios, les corresponde dentro del campo de la producción artística y en consecuencia conservarlos adecuadamente.

En primer lugar, el mobiliario constituye un valioso documento de nuestra memoria histórica gracias a los datos que aporta sobre el devenir humano.Todo mueble es reflejo del clima social, cultural, científico y tecnológico en que fue creado, así como de las sucesivas fases que le tocó vivir hasta llegar a nosotros.

Un ejemplo ilustrativo al respecto sería el mueble Imperio que expresa, en mayor medida que la pintura o la escultura, los delirios de grandeza de Napoleón Bonaparte 3 . O también, entre otros muchos, el de los sobrios y a su vez elegantes ejemplares Biedermeier que constituyen un indiscutible testimonio de la mentalidad y forma de vida de sus destinatarios ${ }^{4}$, amantes de una vida hogareña discreta aunque cargada de comodidades.

Por otra parte, son innumerables los muebles que poseen un indiscutible valor artístico. Y es que, como opina Argan: "las técnicas operativas de la artesanía, en determinados momentos, produjeron valores de arte absoluto"5. Basta recordar aquí la belleza espectacular de los ejemplares de Filippo Parodi. Los esplendidos muebles de Pietro Piffetti (quien a menudo recurre al uso de los materiales más insólitos, para sus marqueterías). El de los arcones florentinos del siglo XVI, exquisitamente pintados por artistas de la talla de Boticcelli o de Paollo Uccello. El de las fascinantes piezas de Riesener, algunas de las cuales Pierre Verlet definió como inmateriales ${ }^{6}$. El de los escultóricos muebles de Andrea Brustolón.Y un largo etcetera de objetos que, en palabras de Samuel Levi: "se convierten en una joya para los ojos de aquellos que los contemplan, quienes disfrutan observándolos de una manera casi sensual."

Por último no podemos dejar de mencionar el valor simbólico del mobiliario. Muchos muebles ostentan una fortísima resonancia simbólica que puede manifestarse tanto a través de su propia tipología, como en la decoración o en los materiales empleados para su ejecución. En estos objetos metafóricos, como diría Marc Auge, su principal valor reside precisamente en la metáfora contenida en ellos, más que en una estricta función de uso ${ }^{7}$. No olvidemos que en determinadas épocas y culturas, ciertas tipologías tenían un carácter representativo. Es decir eran expresión de autoridad social, politica o religiosa como el trono o la cama de aparato. En lo que se refiere a los motivos decorativos, éstos en algunos momentos y lugares poseyeron un marcado simbolismo. Según Battisti los motivos zoomórficos tan habituales en los muebles de la Antigüedad, podrían responder al deseo de conferirles una connotación antropomórfica. De este modo, el asiento con los pies de animal cobraba vida y "se convertía en un solitario y paciente animal que ejercía de intermediario entre el que se sentaba y la tierra"8.

\section{La interpretación de las obras de mobiliario}

En las siguientes líneas, pasaremos a referirnos a la necesidad de que el restaurador sea capaz de interpretar correctamente cada una de las obras que se le confían a la hora de programar la intervención. De esta manera podrá conservar, no sólo la materia sino 
también la identidad del objeto, con el fin de que éste pueda ser transmitido en toda su integridad a las generaciones venideras.

Esta interpretación, al igual que sucede con el resto de los Bienes Culturales, debe darse tras un estudio historico-cientifico de la obra que tenemos entre manos cuyo objetivo consistirá en obtener de ella toda la información posible, desde un punto de vista histórico, matérico y técnico.

Dicho estudio representa un requisito ineludible, independientemente del aspecto estético, antigüedad o valor crematístico del mueble a restaurar. Y tanto si éste pertenece al ámbito público como al privado. Es decir no debe reservarse exclusivamente a los ejemplares supuestamente "excepcionales" ya que ésto significaría que es lícito actuar de forma mecánica en aquellos que se consideran (frecuentemente de manera subjetiva y con escaso criterio), menos preciados. Algo que, sin embargo desafortunadamente, aún suele ser habitual en nuestros días. De hecho todavía, en muchos casos parecen no existir impedimentos para que se actue sobre los muebles de manera irreflexiva, por lo general en respuesta a las exigencias de una clientela poco consciente del significado cultural del mobiliario. $O$ de un mercado que, a menudo, lejos de respetar estas obras, las considera como puras mercancías.

Como sabemos este estudio histórico-científico, indisociable por tanto, de cualquier proceso de restauración, debe perseguir un doble objetivo: conservativo y cultural.

- El primer objetivo consiste en llegar a conocer profundamente las características del mueble que se va a restaurar con el fin de poder atender correctamente a sus necesidades conservativas.

- Por su parte, la finalidad cultural de este estudio se refiere a la necesidad de aprovechar la ocasión privilegiada que nos brinda el contacto directo con la obra.para llevar a cabo una intensa labor de investigación. Una investigación que ya no estará sólo supeditada a la propia intervención, sino al conocimiento global de esta tipología artística. De hecho los datos, fruto de dicho estudio, redundarán en provecho de la historia del mueble.

Si bien es cierto que este segundo objetivo ${ }^{9}$ es importante para todo tipo de Bienes culturales, resulta ser fundamental en el caso de los muebles. Ello se debe a que las referencias bibliográficas sobre algunas cuestiones, como por ejemplo los procedimientos técnicos de los mismos, no son aún todo lo extensas y precisas que desearíamos.

En concreto, para el estudio histórico se requerirá, en primer lugar, de un detenido examen visual del mueble, contemplando todos los aspectos presentes en el mismo (etiquetas, inscripciones, etc) que puedan aportar algún tipo de información 10. Seguidamente será necesario consultar todas aquellas fuen- tes documentales que permitan ahondar en el conocimiento de la obra. Como es evidente también será necesario contar, para este estudio, con la colaboración del historiador del mueble.

El estudio cientííco, nos proporcionará determinados datos imprescindibles para profundizar en las características técnicas y matéricas del mueble que tenemos entre manos. Es decir, este estudio se hace necesario para todos aquellos aspectos donde no llega "el ojo ejercitado" del restaurador o del historiador ni tampoco la investigación histórica. Además permitirá corroborar ciertos resultados obtenidos previamente por dichos profesionales. Pero para que esta labor de investigación histórica-científica resulte ser válida, es indispensable que el restaurador sea capaz de determinar cuales son los objetivos que se persiguen en cada momento, así como el tipo de información que desea conseguir. Asimismo debe de poder interpretar los datos que le proporciona tanto el analista como el historiador "I.

Los resultados de este doble estudio a que nos venimos refiriendo, revelarán de manera pormenorizada las características de la pieza que tenemos entre manos y también su problemática matérica y patología. De esta manera podremos situarla en un contexto cultural y geográfico determinado así como emitir un diagnóstico acertado sobre su estado de conservación.

Conviene recordar que este estudio no se agota con el inicio de la intervención. Es tarea y responsabilidad del restaurador el seguir interpretando todos aquellos aspectos significativos que va descubriendo durante el proceso de restauración.Y por supuesto, cuando sea necesario, mediante el auxilio de nuevas analíticas científicas y/o de las pertinentes consultas a las fuentes bibliográficas, al historiador o a otros profesionales.

Como vemos, la interpretación de las obras del mobiliario no puede reducirse a una simple descripción del objeto a restaurar. Debe de entenderse, más bien, como el fruto de un intenso dialogo entre el restaurador y la obra. Pero, como es evidente, para que este dialogo resulte ser eficaz, dicho profesional deberá estar estrechamente familiarizado con esta tipología artística y a su servicio.

De hecho determinados signos externos de la obra, en muchos caso, solo podrán ser percibidos por su "ojo y tacto expertos". Y precisamente durante un proceso de restauración que es cuando ésta se ve "entre bastidores". Momento privilegiado en el que es posible captar y descifrar determinados mensajes estéticos ligados, por ejemplo, a la elaboración artesanal. Unos mensajes que, además de ofrecernos información sobre los procedimientos técnicos de la obra, o sobre otras valiosas cuestiones, pueden contener una rica carga expresiva. Así, los golpes de gubia, las calidades de una marquetería o la sofisticación de un acabado, reflejan la lucha del artesano con la materia. Reflejan el cansancio de su mano, el sudor de su frente e 
incluso los latidos de su corazón. Estos sutiles signos externos nos permiten, en definitiva, apreciar la poética y la sintaxis de una obra de mobiliario

\section{Cuestiones de método. La reparación estructural}

Una vez interpretada correctamente la obra, se podrá proceder a intervenir en ella con el fin de conservar su materia y recuperar su legibilidad, en los casos en que ésta se vea comprometida. Obviamente, esta última acción evitará en todo momento, infringir daños en la misma o recurrir a arbitrariedades. En caso contrario deberá eludirse absolutamente.

La intervención en el mobiliario requiere de una metodología que tenga en cuenta la propia especificidad de este tipo de obras. Es decir, será necesario emplear una metodología pensada para el mueble y "desde" el mueble, evitando actuar mecánica y sistematicamente por analogía con otros campos de la restauración.Y así, mediante el adecuado empleo de criterios y métodos específicos, será posible garantizar el mantenimiento de la auténtica naturaleza de este tipo de objetos, respetando las peculiaridads estéticas, técnicas y funcionales que los caracterizan culturalmente.

Para ilustrar mejor este planteamiento, nos referiremos brevemente a una de las fases de la restauración-conservación de mobiliario: la reparación estructural. Una fase que responde a determinadas exigencias propias de esta tipología y distantes de las de otros Bienes culturales. Dicha operación, que reviste en numerosas ocasiones una gran trascendencia, ya que debe de ser eficaz sin por ello desvirtuar la identidad y el proyecto técnico del mueble, puede responder a motivos conservativos, de legibilidad o a ambas cosas a la vez. En el primer caso, tiende a resolver los problemas estructurales que afectan a la supervivencia física de los muebles. Ejemplo de ello sería la reposición de aquellos elementos de sustentación ausentes de la obra e imprescindibles para la recuperación de su estabilidad. Este sería el caso de la reproducción de un ensamble desaparecido, la realización de un pie etc.

Por su parte, como ya hemos dicho, la reparación estructural también se puede llevar a cabo por cuestiones de legibilidad, en aquellos casos en que el propio deterioro del mueble impide la correcta lectura del mismo en todas sus dimensiones.

Ilustremos esta cuestión mediante el ejemplo de un mueble al que le faltara una pata En dichas circunstancias éste, además de no mantenerse en pie, con el consiguiente perjuicio para su supervivencia, se encontraría en un estado fragmentario y además su órden racional 12 habría cambiado. Es decir si el mueble fuera, pongamos por caso, una silla habría dejado de serlo para convertirse en otra cosa. Si se nos permite la ironía podría quizá asemejarse más ahora a una

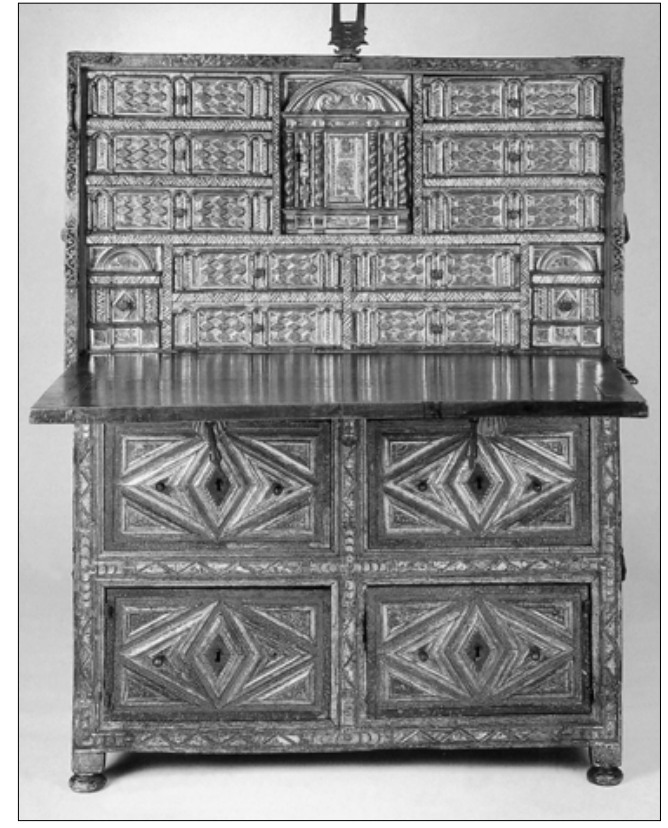

Fig I. Bargueño español. Siglo XVII. Colección SantanderCentral Hispano. obra de arte contemporáneo. Evidentemente, ante casos como el expuesto resultaría necesario reponer el mencionado elemento sustentante Abundando en este argumento de la recuperación de la legibilidad a través de la reparación estructural, podemos imaginar un bargueño u otro tipo de mueble cuyos problemas estructurales impidieran observar su suntuoso interior (Fig I). Aquí no habría más remedio que intervenir, siempre que el estado de conservación del objeto lo permitiera, con el fin de que éste pudiera exhibirse por entero y permitir así una más completa fruición visual del mismo ( Fig 2,3). En esta línea se situaría también la reparación estructural de un mueble mecánico del s.XVIII, cuando la rotura, el desgaste o la pérdida de determinados elementos, imposibilitaran que éste pudiera ser contemplado en toda su integridad.

Este tipo de muebles poseían un carácter multifuncional y fueron concebidos para responder a las más variadas y caprichosas funciones. En ellos se combinaba la búsqueda de la comodidad con el deseo de impresionar, crear sorpresa y provocar admiración mediante la invención de ingeniosos mecanismos. Mecanismos ocultos que, a modo de trucos, debían de ser descubiertos y accionados para desvelar los secretos contenidos en sus llamativos interiores (Fig4). Objetos pensados para jugar con la mirada del espectador, ya que semejaban ser, a simple vista, lo que no eran o sólo una parte de lo que eran. Muebles que podríamos definir como "interactivos" -si se nos concede la licencia de emplear este término- debido a que, sólo se podían despojar de su engañosa apariencia al ser manipulados ${ }^{13}$. Es decir una mesa mecánica, a primera vista, podía parecer sólo una mesa con un tablero y unas patas pero si se accionaban sus mecanismos podía responder a multiples usos y convertirse en varias mesas o incluso en diferentes muebles a la vez: una escalera, un reclinatorio, etc (Fig5). Podríamos traer aquí a colación la mesa "Arlequín",obra de Abraham Roentgen que se 
늠

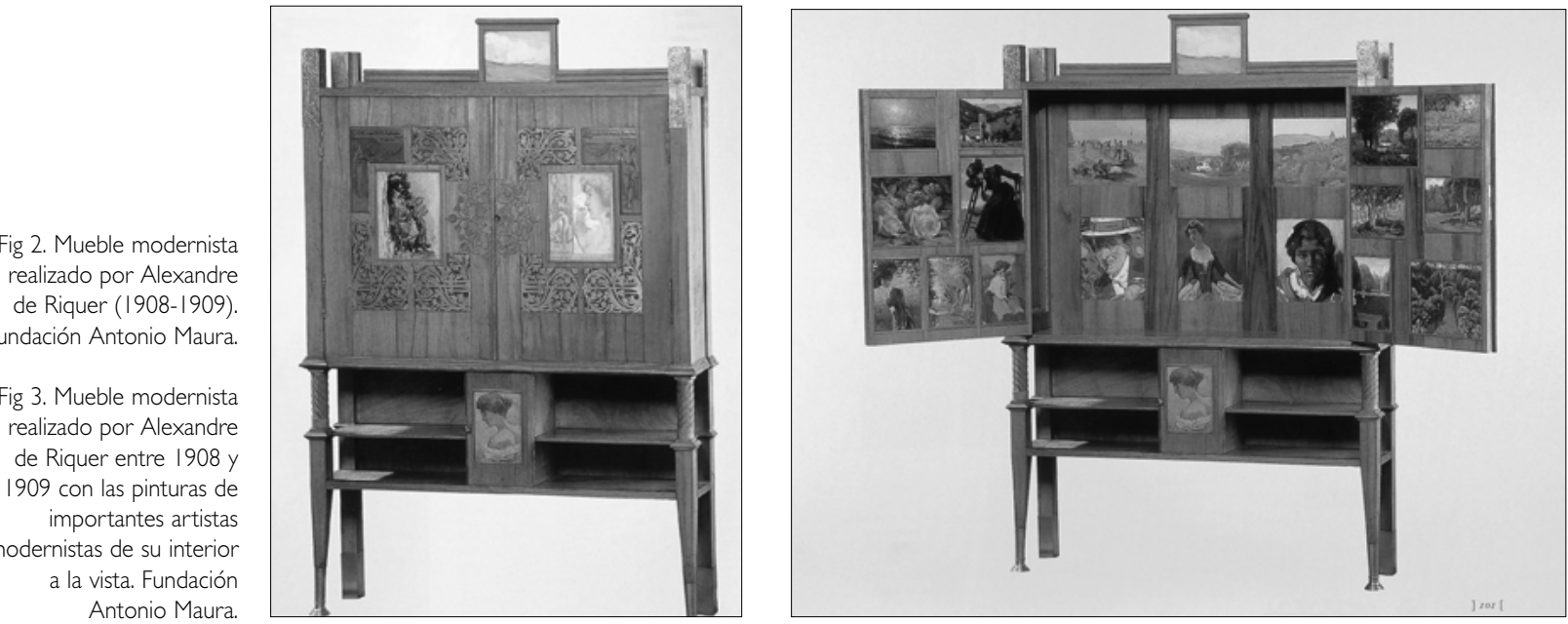

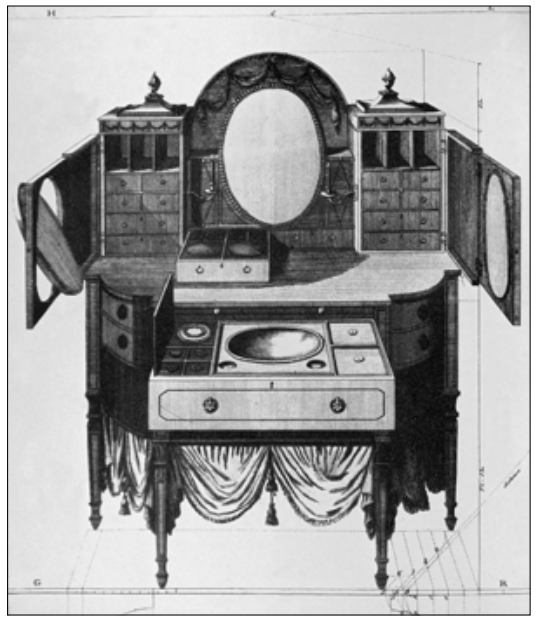

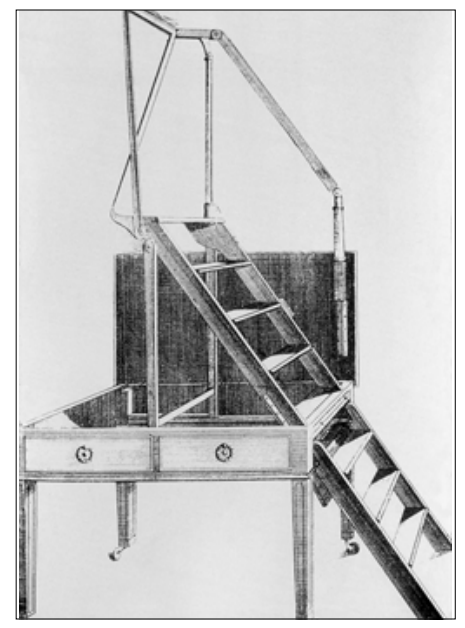

Fig 4.Tocador de señora. Diseño de Sheratón. Ingaterra. Siglo $\mathrm{XVIII.}$

Fig 5. Mesa escalera. Diseño de Sheratón. Ingaterra. Siglo XVIII. expone en el Mª Victoria \& Albert de Londres 14. Esta mesa contiene en su interior varios tableros: uno de juego, otro para escribir y un tercero compartimentado para guardar diversos objetos (Fig 6,7).

Otro ejemplo de mueble mecánico lo tenemos en el famoso "secreter de cilindro" realizado por Jean François Oeben para Luis XV. Este escritorio presenta una alzada que se cierra con una tapa semicilíndrica y se abre mediante un giro de llave que hace que ésta se levante de golpe enrollándose sobre sí misma y desapareciendo en el interior. El mismo giro de llave desbloquea todos los cajones internos. Dos cajoncitos para tinteros salen por los lados al accionar un pulsador, sin que sea necesario abrir el mueble. De este modo los criados del rey podían renovar la tinta sin curiosear en sus documentos y pertenencias (Fig 8).

Una tercera obra maestra de mecánica sería la "mesa a la borgoñona", cuyo artífice fue también el genial Oeben. Cerrado, este mueble aparenta ser una pequeña cómoda vertical, con seis cajones. Pero se ve transfomado mediante la manipulación de complicados mecanismos. De la base del mueble se alza un estante para libros, a cuyos lados se sitúan dos elementos semicirculares que sirven para contener un servicio de cuchillos y tenedores. A través de algunos cajones centrales -que en realidad son puertecillas -y mediante la acción de ciertos resortes, se ac- cede a un compartimento que custodia objetos de escribir. Otros dispositivos proporcionan un reclinatorio y un escritorio para ser usado en la cama.

Resulta facil comprender que este tipo de muebles pierden gran parte de su identidad y de su razón de ser cuando no se pueden contemplar integramente. Es decir cuando sus inteligentes mecanismos ya no se pueden accionar para revelar su rico interior. Cuando nos resulta imposible admirar los virtuosos alardes técnicos contenidos en ellos y entender como funcionaban y cuales eran las multiples prestaciones que ofrecían.

Por eso ante el deterioro de estos objetos no podemos conformarnos con mantener una parte del "todo", ya que la "parte" sin el "resto" carece de significado. Como hemos visto, es precisamente en el "resto", en esa zona oculta de su interior donde se esconde lo más interesante y singular (Fig 9, I0).

De ahí que valga la pena restaurar adecuadamente estos inteligentes muebles cuando así se requiere. Por supuesto actuando siempre con el máximo respeto y solamente si su estado de conservación nos lo consiente. Ahora bien, la restauración no tendrá como objetivo prioritario el que puedan volver a ser usados. Lo más probable es que ésto ya no sea posible debido a su propio envejecimiento, pero sí podrá recuperar su expresividad. En otras palabras, esta acción podrá permitir la exhibición de su esmerada ejecución, de sus trucos y secretos y de sus variadas funciones de uso. Unas funciones de uso que constituyeron el pretexto de la fabricación de estos objetos.

Finalizaremos haciendo alusión a uno de los motivos más frecuentes de intervención en los muebles: las exigencias de uso.

Como sabemos, en la mayoría de los casos, cuando alguien hereda o compra un mueble antiguo pretende utilizarlo, al igual que muchos otros objetos domésticos. Y con esta finalidad, a veces, decide restaurarlo Ahora bien, conviene tener presente que ningún restaurador y ninguna reparación estructural 


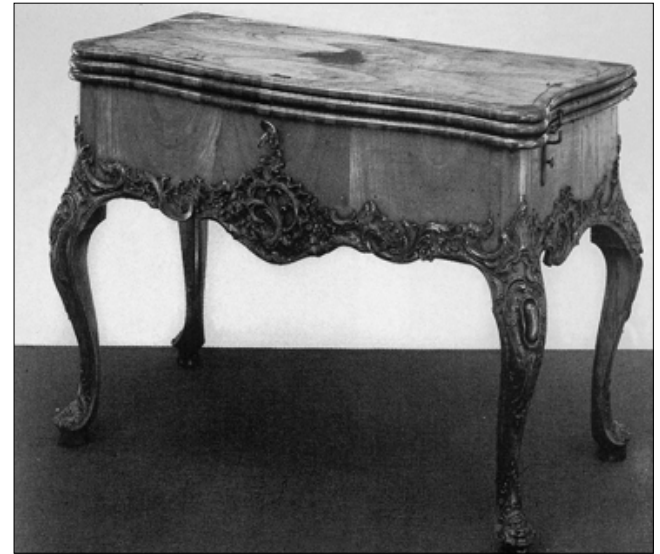

conseguirán que un mueble pueda volver a ser utilizado si su estado de conservación no lo permite. Dicho de otra manera, a veces es imposible compatibilizar el mantenimiento de la integridad física de una obra con las necesidades de uso de su propietario. Ninguna restauración podrá impedir que los ensambles de un asiento por el que han pasado los años se vean debilitados por un uso constante, ni garantizar que los cajones de una cómoda soporten una manipulación continua, ni el que se mantenga integra por mucho tiempo la tapa de un buró sobre la que se escribe a diario.

Los muebles no son como los electrodomésticos (odiosa comparación aunque bastante ilustrativa), que cuando se rompen se reparan y pueden seguir funcionando. La mayoría de ellos, debido al envejecimiento de sus materiales constitutivos, se han vuelto vulnerables al uso. De ahí que ya no puedan seguir ofreciendo las mismas prestaciones que tuvieron en origen, ni siquiera tras haber sido restaurados.

A muchas personas les resulta difícil entender todos estos planteamientos. Por ello, la situación que se crea entre el propietario de un mueble, cuando éste desea usarlo a toda costa, y el restaurador suele constituir uno de los momentos de mayor conflicto entre ambos ${ }^{15}, 16$. Pero el restaurador, deberá mantenerse inflexible y no podrá someterse a los requerimientos que se le exigen a costa de las obras aún a riesgo de perder un trabajo o incluso un cliente. Podemos estar seguros de que si esta actitud se difundiera, los muebles del pasado dejarían de verse afectados sistemáticamente por intervenciones incorrectas. Intervenciones que pretenden borrar de un plumazo el paso del tiempo depositado sobre los mismos, a fin de recuperar a ultranza una hipotética utilidad. Este sería el caso de determinados tratamientos de desalabeo de la madera, que comportan riesgos para las obras. En definitiva, dado que no es viable el rejuvenecimiento de los muebles antiguos, ni tampoco deseable, nos vemos obligados a aceptarlos con los"achaques" y, al mismo tiempo, el "encanto de su edad".

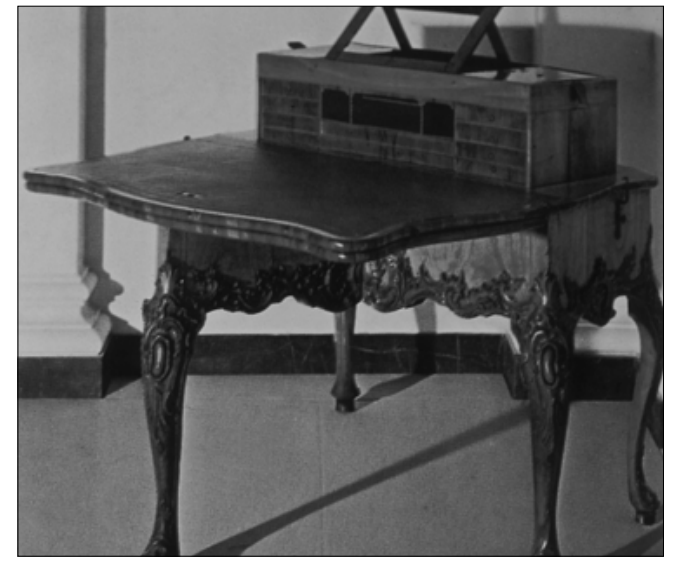

$\varangle$

ш
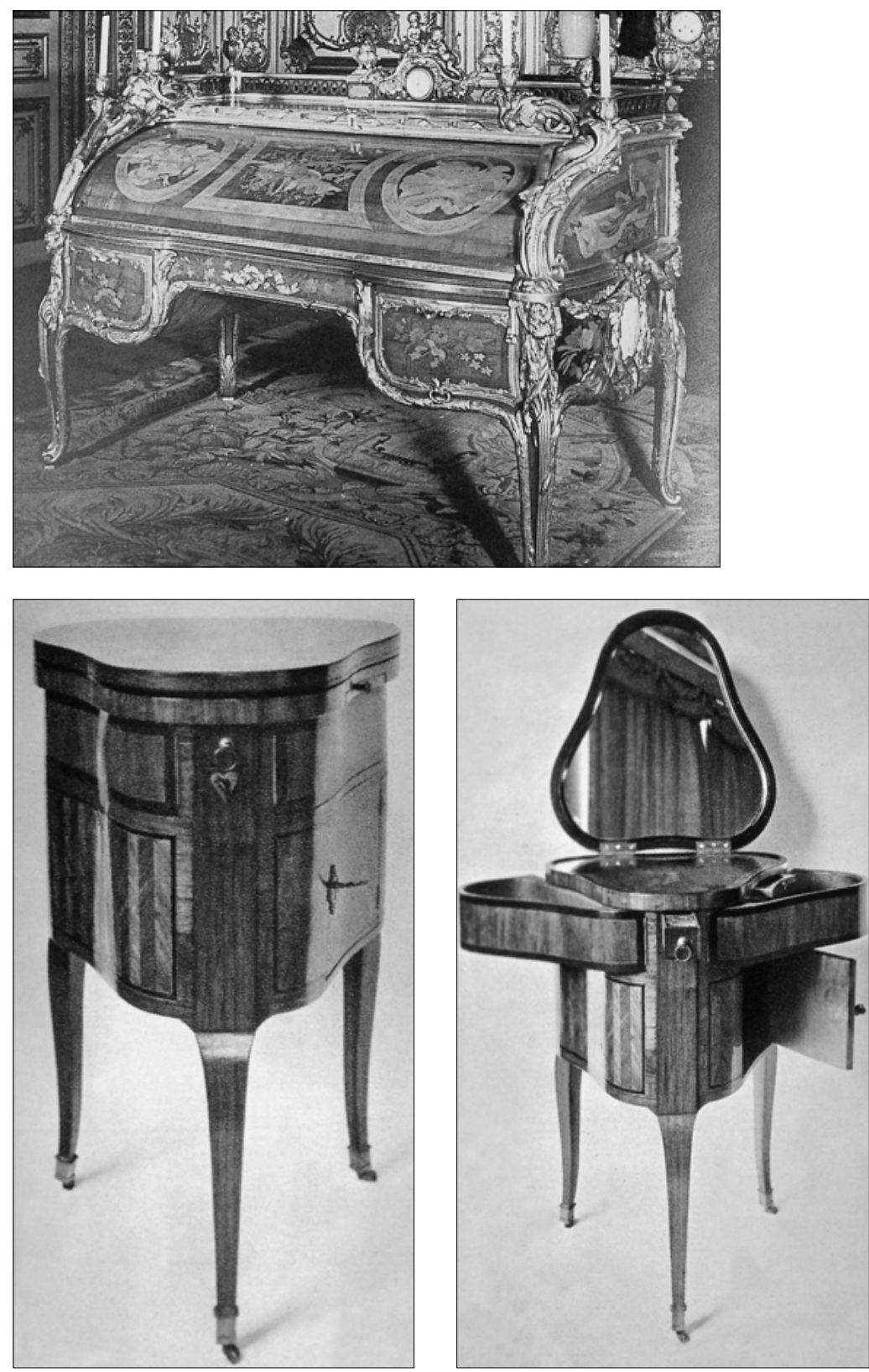

Fig 8. Buró de cilindro de Jean Françoise Oeben realizado en el siglo XVIII para Luis XV.

Fig 9. Tocador para hombre realizado por Cordie. Francia, siglo XVIII.

Fig IO. El tocador de la figura 9 abierto. Cordie. Francia, siglo XVIII.
Fig 6. Mesa Arlequín de Abraham Roentgen. Siglo XVIII. Museo Victoria \& Albert. Londres.

Fig 7. La mesa Arlequín de Abraham Roentgen (fig 6) abierta. Siglo XVIII. Museo Victoria \& Albert. Londres. 
ALVAR GONZALEZ PALACIOS. Enciclopedia delle Arti Decorative. Editorial Fabri. Milán 1981.

ALVAR GONZALEZ PALACIOS. Mobili e Stili. Fratelli Fabri Editori. Milán. 1.975.

ARGAN,G.C. Progetto e destino. II Saggiatore, Milán 1.965.

A.A.V.V. Mueble español, estrado y dormitorio. Catálogo de la exposición. Comunidad de Madrid 1990.

Cassoni italiani delle collezioni d“arte dei Musei Sovietici. Ed. Aurora Art Publishers. Leningrado 1983.

CHEVALIER, JEAN y GHERBANT, ALAIN. Diccionario de los símbolos. Ed. Herder. Barcelona 1991.

DAMPIERRE, Florence de. The best of painted furniture. Ed. Weidenfeld and Nicolson. Londres 1987.

DE FUSCO, Renato. Storia dell'arredamento. Editorial Utet. Turin 1985.
FLEMING, John y HONOUR, Hugh. Diccionario de las artes decorativas. Alianza Editorial S.A... Madrid 1987

LUCIE SMITH, Edward. Breve historia del mueble. Ediciones del Serbal. Barcelona 1988.

ORDOÑEZ,C. ORDOÑEZ,L Y ROTAECHE,M., El mueble. Conservación y restauración. Ed. Nardini-Nerea. Florencia 1997.

ORDOÑEZ,C. ORDOÑEZ,L Y ROTAECHE,M. Restauración de mobiliario. Revista Anticuaria 1996. Números 138, 139, 140.

RITCHER, Gisela. Ancient furniture. A history of Greek, Etruscan and Roman furniture. Oxford University Press 1926.

VERLET PIERRE. Le mobilier Royal Français. Ed. Picard París 1992.

WILKIE, Angus. Biedermeier. Ed. Abbe Ville Press. Nueva York. s.f.

WILLS, Geoffrey, BARONI, Daniela y CHIARELLI, Brunetto. EI mueble, historia, diseño, tipos y estilos. Ed. Grijalbo. 1985.

\section{Notas}

I. En palabras del historiador Juan José Junquera: "en estas obras se logra con frecuencia un difícil equilibrio entre belleza y función, entre lo gratuito y lo útil." Presentación del Curso "Las otras artes". Catálogo de los cursos de Verano de "El Escorial". Universidad Complutense de Madrid. Año 1.998.

2. Alvar Gonzalez Palacios "Mobili e Stili". Fratelli Fabri Editori.Milán. I.975.

3. Alvar Gonzalez Palacios. "Enciclopedia delle Arti Decorative". Dirigida por Alvar González Palacios. Editorial Fabri. Milán 1.981.

4. El estilo Biedermeier se desarrolla entre 1.815 y 1.848 y encarna el espíritu del burgués medio alemán y austriaco de esa época, quien hace de su casa su refugio y a la vez su reino.

5. Argán,G.C."Progetto e destino".II Saggiatore, Milán I.965.

6. Verlet, Pierre. "Le mobilier Royal Francais".. Ed. Picard París 1992

7. Auge,Marc."Conferencia impartida en el Instituto Europeo di Design" Madrid I.999.

8. De Fusco,R،“'Storia dell'arredamento".Utet.Turín 1985.

9. En palabras de Emilio Ruiz de Arcaute :..."practicamente no existen posibilidades de estudios técnicos fuera de los procesos de restauración. Por ello en estos momentos se debe de aprovechar la ocasión para obtener una información más completa" Revista "Kermes." número 29. Mayo-Agosto I.997. Editorial Nardini.
10. Conviene hacer hincapié en la importancia de este exámen visual ya que la mayor parte de los muebles son anónimos (carecen de fecha y de firma). Por otra parte, una extensa producción de los mismos queda aún por catalogar. Además, por lo general, aquellos que han sido restaurados carecen de adecuados informes de restauracion.

I I. En caso contrario, sólo se conseguirá llevar a cabo una mera recopilación de datos carentes de significado.

12. Aquellos aspectos que definen una determinada tipología

13. Estos muebles eran propios de una época en la que la técnica era capaz de crear maravilla y estupor. Recordemos a este respecto los extraordinarios autómatas mecánicos que por entonces servían de distracción en las más importantes Cortes europeas.

14. Su nombre viene del "Arlequín" de la Comedia del Arte que sale de una caja con muelles. En el Museo Victoria \& Albert recibe la denominación de "Card-table".

15. siempre que el restaurador posea la ética profesional necesaria para el ejercicio de su profesión.

16. Huelga señalar que esta situación solo tiene lugar cuando se trata de muebles pertenecientes al sector privado. 